\title{
Systematic drug repositioning through mining adverse event data in ClinicalTrials.gov
}

\author{
Eric Wen Su ${ }^{\text {Corresp.. }}{ }^{1}$, Todd M Sanger ${ }^{1}$ \\ ${ }^{1}$ Advanced Analytics Hub, Eli Lilly and Company, Indianapolis, Indiana, United States of America \\ Corresponding Author: Eric Wen Su \\ Email address: ewsu@lilly.com
}

Drug repositioning (i.e. drug repurposing) is the process of discovering new uses for marketed drugs. Historically, such discoveries were serendipitous. However, the rapid growth in electronic clinical data and text mining tools makes it feasible to systematically identify drugs with the potential to be repurposed. Described here is a novel method of drug repositioning by mining ClinicalTrials.gov. The text mining tools I2E (Linguamatics) and PolyAnalyst (Megaputer) were utilized. An I2E query extracts "Serious Adverse Events" (SAE) data from randomized trials in ClinicalTrials.gov. Through a statistical algorithm, a PolyAnalyst workflow ranks the drugs where the treatment arm has fewer predefined SAEs than the control arm, indicating that potentially the drug is reducing the level of SAE. Hypotheses could then be generated for the new use of these drugs based on the predefined SAE that is indicative of disease (for example, cancer). 
4 Systematic Drug Repositioning through Mining

5 Adverse Event Data in ClinicalTrials.gov

6

7 Eric Wen Su ${ }^{1}$, Todd M. Sanger ${ }^{1}$

8

9 'Advanced Analytics Hub, Eli Lilly and Company, Indianapolis, IN, USA.

10

11 Corresponding Author:

12 Eric Su ${ }^{1}$

13

14 Email address: ewsu@lilly.com 


\begin{abstract}
Drug repositioning (i.e. drug repurposing) is the process of discovering new uses for marketed drugs. Historically, such discoveries were serendipitous. However, the rapid growth in electronic clinical data and text mining tools makes it feasible to systematically identify drugs with the potential to be repurposed. Described here is a novel method of drug repositioning by mining ClinicalTrials.gov. The text mining tools I2E (Linguamatics) and PolyAnalyst (Megaputer) were utilized. An I2E query extracts "Serious Adverse Events" (SAE) data from randomized trials in ClinicalTrials.gov. Through a statistical algorithm, a PolyAnalyst workflow ranks the drugs where the treatment arm has fewer predefined SAEs than the control arm, indicating that potentially the drug is reducing the level of SAE. Hypotheses could then be generated for the new use of these drugs based on the predefined SAE that is indicative of disease (for example, cancer).
\end{abstract}

\title{
Introduction
}

Drug repositioning (i.e. drug repurposing) involves the identification and development of new uses for existing drugs (Ashburn \& Thor 2004). The best known example of drug repositioning is the serendipitous discovery of the additional use of thalidomide for the treatment of painful sores associated with leprosy. In 1964, Dr. Jacob Sheskin used thalidomide to help a patient sleep, unexpectedly, the thalidomide also healed the patient's sores and eliminated his pain (Ashburn \& Thor 2004; Sheskin 1965). This discovery shows that clinical data could be the most direct and reliable source of drug repositioning.

However, systematic drug repositioning efforts since 1964 have not been based on clinical data. Typical approaches include high-throughput screening of marketed drugs (Qosa et al. 2016), targeted testing of a class of drugs for a new disease area (Wu et al. 2016a), and in silico methods (Hodos et al. 2016; Mullen et al. 2016), usually based on drug-target interactions (Coelho et al. 2016; Zheng et al. 2015).

Described here is a novel approach to drug repositioning using data from randomized clinical trials. Text mining tools have been used to extract serious adverse event (SAE) data, identify drugs with fewer events related to diseases or associated symptoms in the drug arm than in the control arm, and rank the drugs based on the z-score of log odds ratio.

\section{Materials \& Methods}

A text mining query was developed to extract SAE data from clinical trial data posted at ClinicalTrials.gov. ClinicalTrials.gov is a registry of federally and privately funded clinical trials conducted in the United States and around the world, and contains rich biomedical data from over 220,000 studies in 191 countries. The query was built using Linguamatics' I2E, a literature text mining tool based on natural language processing and linguistic analytics (Cormack et al. 2015; Galijatovic-Idrizbegovic et al. 2016). We were not able to perform the data extraction without this commercial tool.

The query (shown in Figure 1) has 4 main elements:

- To extract Serious Adverse Events classified as cancerous, the combined cancer terms and synonyms from MeSH (https://www.nlm.nih.gov/mesh/) and NCI 
62

63

64

65

66

67

68

69

(http://www.cancer.gov/research/resources/terminology) were loaded into the query region "Serious Event Subtitle" of ClinicalTrials.gov (the "Neoplasms" class).

- The same "Neoplasms" class was negated in the "Condition" region to exclude cancer trials.

- To link the SAE counts to the relevant study arm (i.e. drug or placebo etc.), the group (study arm) IDs and description ("Title") were extracted from the Reporting Groups region.

- The wildcard "random*" was required in the Study Design or Official Title region to ensure that only randomized trials are reported.

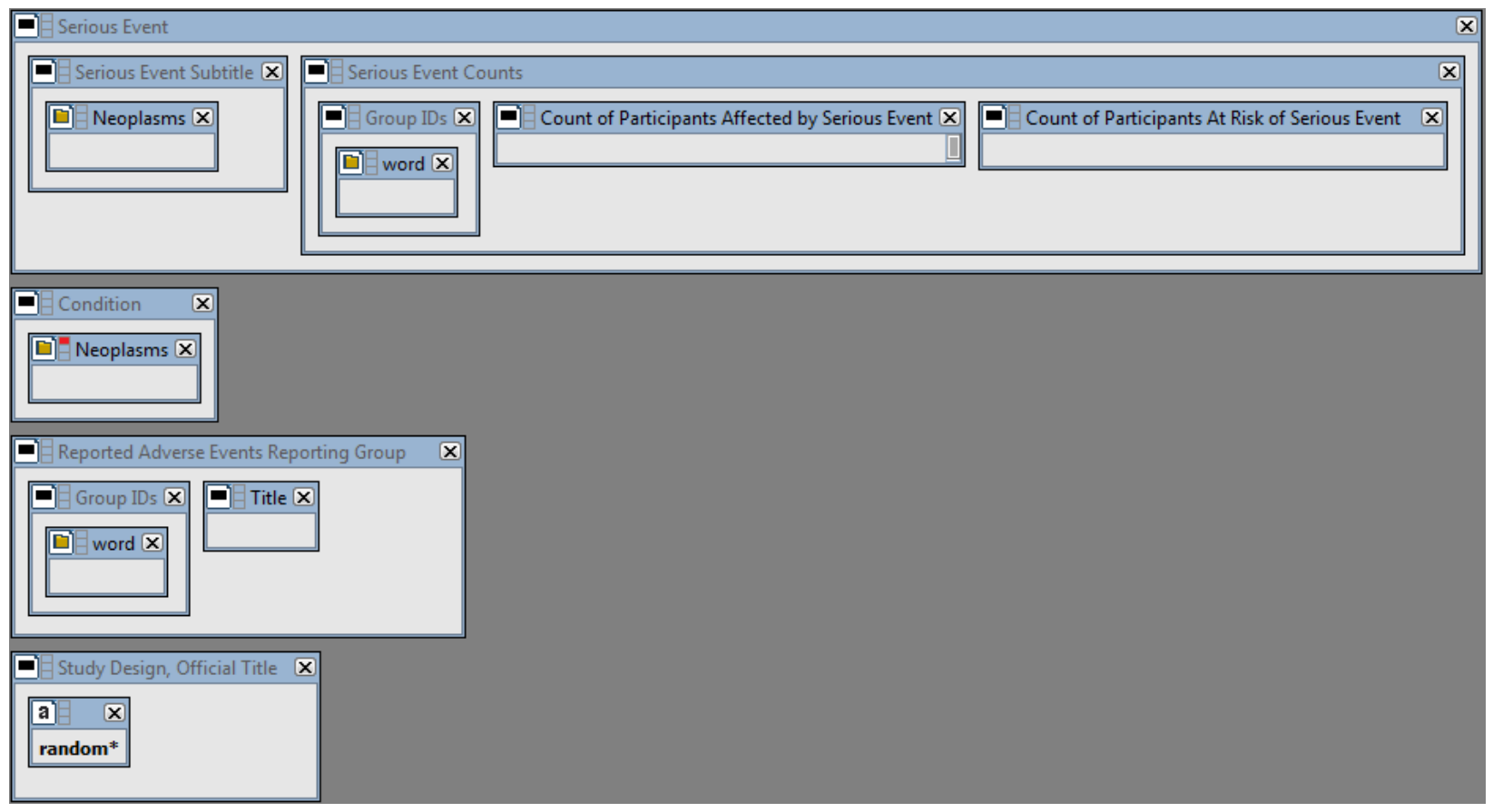

Figure 1. The I2E query. See the "Supplementary information" to reproduce the query by copying and pasting the YAML script into the I2E Pro interface. The query was run on the I2E index that covers the data posted in ClinicalTrials.gov up to August 14, 2016.

The Excel output from the I2E query in Figure 1 was loaded into PolyAnalyst (Megaputer) for reformatting and calculating the odds ratios (OR) and z-score. The final table was sorted by zscore. PolyAnalyst is a commercial text mining tool. The specific tasks described here could also be accomplished by an open-source tool such as KNIME, R, or Python.

The formula for calculating odds ratio (OR), standard error (SE), 95\% confidence interval lower and upper limits (LowerLimit and UpperLimit), and z-score are as follows:

$O R=\frac{D s /(D n-D s)}{C s /(C n-C s)}$ 
90 The distribution of $\log (\mathrm{OR})$ is approximately normal with:

91

$92 S E=\sqrt{\frac{1}{C s}+\frac{1}{C n-C s}+\frac{1}{D s}+\frac{1}{D n-D s}}$

93

94

LowerLimit $=\exp (\log (O R)-1.96 S E)$

95 UpperLimit $=\exp (\log (O R)+1.96 S E)$

96

97

The null hypothesis is that there is no difference between drug and control arm (expected mean

98 OR $=1)$. Therefore,

$z=\frac{\log (O R)-\log (1)}{S E}$ or $z=\log (O R) / S E$

Since the $C s$ and $D s$ are usually small, SE, lower and upper limits, and z-score may not be meaningful for hypothesis testing. However, z-scores are still useful to rank drugs for hypothesis generation on drug repurposing.

Also because of the multiple comparison nature of the algorithm, the results should only be used for hypothesis generation, not for making any conclusion.

For drugs with z-scores $\leq-1.96$, we reviewed the biomedical literature on the drugs, the drug

110 knowledge. The literature review was performed using the text mining tool I2E (Bandy et al.

111 2009).

112

\section{Results}

114 The I2E query in Figure 1 was run on the ClinicalTrails.gov index updated on August 14, 2016.

115 The report contains 105,399 SAE events classified as cancer, from 2861 randomized trials. An

116 example of the extracted data is shown in Figure 2. 
A

Serious Adverse Events

\begin{tabular}{|l|l|l|}
\hline & Daclizumab & Placebo \\
\hline \begin{tabular}{|l|l|} 
Basal cell carcinoma +1 \\
\# participants affected $/$ at risk
\end{tabular} & \\
\hline
\end{tabular}

B

ClinicalTrials.gov

ID

Serious Adverse

Event

Study Arm

Number of Number

(1)

$\underline{\text { NCT00048165 }}$

Basal cell carcinoma

Basal cell

$\underline{\text { NCT00048165 }}$ carcinoma

NCT00048581

BASAL CELL CARCINOMA

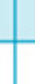

\begin{tabular}{|l|r|r|}
\hline Daclizumab & 4 & 216 \\
\hline
\end{tabular}

\begin{tabular}{|c|c|c|c|c|}
\hline DNC & CARCINOMA & (RDM) & 1 & \\
\hline NCT00048581 & $\begin{array}{l}\text { BASAL CELL } \\
\text { CARCINOMA }\end{array}$ & Placebo (PLA) & 0 & 133 \\
\hline NCT00089661 & $\begin{array}{l}\text { Benign breast } \\
\text { neoplasm }\end{array}$ & $\begin{array}{l}\text { Denosumab } 60 \\
\text { mg Q6M }\end{array}$ & 0 & 129 \\
\hline NCT00089661 & $\begin{array}{l}\text { Benign breast } \\
\text { neoplasm }\end{array}$ & Placebo & 1 & 120 \\
\hline NCT00089661 & $\begin{array}{l}\text { Benign ovarian } \\
\text { tumour }\end{array}$ & $\begin{array}{l}\text { Denosumab } 60 \\
\text { mg Q6M }\end{array}$ & 1 & 129 \\
\hline NCT00089661 & $\begin{array}{l}\text { Benign ovarian } \\
\text { tumour }\end{array}$ & Placebo & 0 & 120 \\
\hline
\end{tabular}

118 Figure 2. An example of the data extracted from ClinicalTrials.gov (A) into Excel (B) by

119 the I2E query described above. The top two rows in B show the data extracted from the table

120 in A. The precision of the I2E query described above is $100 \%$, and the recall is estimated as $99 \%$

121 assuming $1 \%$ of the cancer terms that the trial sponsors used are not among the cancer synonyms 122 collected by MeSH or NCI.

123

124 The I2E output table was reformatted as illustrated in Table 1 to have one row per trial per SAE

125 (type of cancer). 


\begin{tabular}{|c|c|c|c|c|c|c|c|}
\hline $\begin{array}{l}\text { ClinicalTrials } \\
\text { gov ID }\end{array}$ & \begin{tabular}{|l} 
Serious \\
Adverse \\
Event
\end{tabular} & $\begin{array}{l}\text { Number of } \\
\text { patients } \\
\text { with SAE } \\
\text { in control } \\
\text { arm } \\
\end{array}$ & $\begin{array}{l}\text { Number of } \\
\text { patients in } \\
\text { control } \\
\text { arm }\end{array}$ & $\begin{array}{l}\text { Control } \\
\text { Arm }\end{array}$ & \begin{tabular}{|l|} 
Number of \\
patients \\
with SAE in \\
drug arm
\end{tabular} & $\begin{array}{l}\text { Number of } \\
\text { patients in } \\
\text { drug arm }\end{array}$ & Drug Arm \\
\hline NCT00089791 & $\begin{array}{l}\text { Bladder } \\
\text { cancer }\end{array}$ & 3 & 3876 & Placebo & 4 & 3886 & $\begin{array}{l}\text { Denosumab } \\
60 \text { mg Q6M }\end{array}$ \\
\hline NCT00089791 & $\begin{array}{l}\text { Breast } \\
\text { cancer }\end{array}$ & 25 & 3876 & Placebo & 34 & 3886 & $\begin{array}{l}\text { Denosumab } \\
60 \text { mg Q6M }\end{array}$ \\
\hline NCT00089791 & \begin{tabular}{|l} 
Colon \\
cancer
\end{tabular} & 8 & 3876 & Placebo & 11 & 3886 & $\begin{array}{l}\text { Denosumab } \\
60 \text { mg Q6M }\end{array}$ \\
\hline NCT00120289 & \begin{tabular}{|l|} 
Lung \\
neoplasm \\
malignant \\
\end{tabular} & 14 & 1696 & $\begin{array}{l}\text { Placebo + } \\
\text { Simvastatin }\end{array}$ & 8 & 1718 & $\begin{array}{l}\text { ERN + } \\
\text { Simvastatin }\end{array}$ \\
\hline NCT00120289 & $\begin{array}{l}\text { Malignant } \\
\text { melanoma }\end{array}$ & 4 & 1696 & $\begin{array}{l}\text { Placebo + } \\
\text { Simvastatin }\end{array}$ & 1 & 1718 & $\begin{array}{l}\text { ERN + } \\
\text { Simvastatin }\end{array}$ \\
\hline NCT00120289 & $\begin{array}{l}\text { Non-small } \\
\text { cell lung } \\
\text { cancer } \\
\end{array}$ & 4 & 1696 & $\begin{array}{l}\text { Placebo + } \\
\text { Simvastatin }\end{array}$ & 0.3 & 1718 & $\begin{array}{l}\text { ERN + } \\
\text { Simvastatin }\end{array}$ \\
\hline NCT00143507 & $\begin{array}{l}\text { Colon } \\
\text { cancer }\end{array}$ & 7 & 5430 & Placebo & 5 & 5477 & Ivabradine \\
\hline NCT00143507 & $\begin{array}{l}\text { Rectal } \\
\text { cancer }\end{array}$ & 6 & 5430 & Placebo & 3 & 5477 & Ivabradine \\
\hline
\end{tabular}

Table 1. A sample of the reformatted table.

130 If a row has less than 3 patients with SAE in the control arm, it is deleted. This is because the goal is to find drugs that have fewer cancer SAEs in the drug arm than in the control arm. After the deletions, the table has only 601 rows left.

If a row has 0 patients with SAE in the drug arm, the 0 value is replaced with 0.3 . These replacements enable the ranking of the drugs that have no cancer SAE in the drug arm. Without the replacements, all such rows will have zero for OR and minus infinity for the z-score.

138 The final table with calculated columns is shown in Table 2. The drugs were ranked by sorting 139 the $\mathrm{z}$-score from the lowest value to the highest. 
140

141

142

143

144

145

146

147

148

149

150

151

152

153

154

155

156

157

158

159

160

161

162

163

164

165

166

167

168

169

170

171

\begin{tabular}{|c|c|c|c|c|c|c|c|c|c|c|c|c|}
\hline rug & $\begin{array}{l}\text { Serious } \\
\text { Adverse } \\
\text { Event }\end{array}$ & Ds & Dn & Cs & Cn & Control & SE & OR & \begin{tabular}{|l|} 
Lower \\
Limit
\end{tabular} & $\begin{array}{l}\text { Upper } \\
\text { Limit }\end{array}$ & $z$ & $\begin{array}{l}\text { ClinicalTrials } \\
\text { gov ID }\end{array}$ \\
\hline V501 & & 20 & 480 & 46 & 468 & Placebo & 0.28 & 0.40 & 0.23 & 0.69 & -3.33 & NCTO \\
\hline \begin{tabular}{|l} 
Clopid \\
Telmis \\
\end{tabular} & & 4 & 5000 & 14 & 5023 & & 0.57 & 0.29 & 0.09 & 0.87 & -2.20 & NCTOC \\
\hline Vorapaxar & $\begin{array}{l}\text { RECTA } \\
\text { CANCE }\end{array}$ & 4 & 13186 & 13 & 13166 & Placebo & 0.57 & 0.31 & 0.10 & 0.94 & -2.06 & NCT00526474 \\
\hline Phylloquinone & Cancer & 3 & 217 & 11 & 223 & Placebo & 0.66 & 0.27 & 0.07 & 0.98 & -1.99 & NCT00150969 \\
\hline $\begin{array}{l}\text { Clopidogrel + } \\
\text { ASA }\end{array}$ & $\begin{array}{l}\text { Pancreatic } \\
\text { carcinoma }\end{array}$ & 1 & 3772 & 8 & 3782 & $\begin{array}{l}\text { Placebo + } \\
\text { ASA } \\
\end{array}$ & 1.06 & 0.13 & 0.02 & 1.00 & -1.96 & NCT00249873 \\
\hline $\begin{array}{l}\text { Core-phase: } \\
\text { Aliskiren }\end{array}$ & $\begin{array}{l}\text { Gastric } \\
\text { cancer }\end{array}$ & 1 & 4272 & 8 & 428 & $\begin{array}{l}\text { Core- } \\
\text { phase: } \\
\text { Placebo }\end{array}$ & 1.06 & 0.13 & 0.02 & 1.00 & -1.96 & NCT00549757 \\
\hline
\end{tabular}

Table 2. The final table with calculated columns. The rows are sorted by z-score. Only the top 6 rows are shown (see Supplementary information for all 162 rows with $\mathrm{z}<-1$ ). $D s=$ Number of patients with SAE in Drug arm; $D n=$ Number of patients in Drug arm; $C s=$ Number of patients with SAE in Control arm; $C n=$ Number of patients in Control arm. The original indications of the trials were (from top to bottom): HPV Infections, Stroke, Atherosclerosis, Osteoporosis, Atrial Fibrillation, and Type 2 Diabetes.

The results in Table 2 could range from false positive findings to possible signals for drug repositioning hypotheses. Therefore, we evaluated the drugs for cancer by other research from the current biomedical literature.

The V501 vaccine (Table 2, Row 1) arm had less cervical dysplasia events than control in a clinical trial on the prevention of papillomavirus infection. Papillomavirus is already known to be associated with cervical dysplasia (Firnhaber et al. 2009), a precursor lesion of cancer of the cervix (Kesic et al. 1990). We consider this top hit as a positive control that supports the credibility of our approach, since the prevention of the viral infection would naturally lead to the prevention of cervical dysplasia.

The data in Table 2, Row 2 suggest that Telmisartan might be useful to prevent colon cancer (note that Clopidogrel is in both the Drug and Control arm, so we did not investigate Clopidogrel further). Recent cell-based studies reported that Telmisartan exerts anti-tumor effects by activating peroxisome proliferator-activated receptor- $\gamma$ ( $\mathrm{Li}$ et al. 2014; $\mathrm{Pu}$ et al. 2016; Wu et al. 2016b). The algorithm presented here provides the first evidence from a randomized clinical trial, indicating that Telmisartan may be viable as a repurposed prevention for colon cancer.

Phylloquinone (Table 2, Row 4) is a vitamin (vitamin K1) supplement rather than a prescription drug. K vitamins + sorafenib induce apoptosis in human pancreatic cancer cell lines (Wei et al. 2010). A prospective cohort analysis found that individuals who increased their intake of dietary phylloquinone might have a lower risk of cancer than those who did not (Juanola-Falgarona et al. 2014). The data from the randomized trial in Table 2 suggest that vitamin K1 might actually help prevent cancer $(\mathrm{OR}=0.27,95 \% \mathrm{CI}=0.07-0.98)$. The potential cancer prevention by vitamin 
$172 \mathrm{~K} 1$ is especially intriguing because one can get more than $1000 \%$ daily value of vitamin K1 by

173 simply eating one cup of cooked kale or spinach

174 (https://www.healthaliciousness.com/articles/food-sources-of-vitamin-k.php).

175

176

177

178

179

180

181

182

183

184

185

186

187

188

189

190

191

192

193

194

195

196

197

198

199

200

201

202

203

204

205

206

207

208

209

210

211

212

213

214

215

216

The clinical trial in Table 2, row 6 tested Aliskiren for cardiovascular and renal disease in patients with type 2 diabetes. The SAE data from this study show that only 1 out of 4272 patients in the Aliskiren arm reported gastric cancer versus 8 out of 4285 patients in the placebo arm. A recent paper described that Aliskiren inhibits renal carcinoma cell lines proliferation in vitro (Hu et al. 2015). The data from this randomized clinical trial suggest the possible repurposing of Aliskiren for cancer.

Lastly, our literature search found no direct link between Vorapaxar (Table 2, Row 3) or Clopidogrel (Table 2, Row 5) and cancer prevention or treatment. Thus, these data in Table 2 could be the first sign that Vorapaxar or Clopidogrel might be useful for cancer or could be interpreted as false positive findings since we have made no attempt to adjust the multiplicity (multiple comparisons) in this exploratory analysis.

Above are only six outputs from our repositioning algorithm for one type of disease. The method described here could be used to identify other candidates for repositioning on any diseases that are reported as serious adverse events in ClinicalTrials.gov.

\section{Discussion}

Presented here is a novel drug repositioning method that reveals potential new uses of existing drugs directly from clinical trial data. This article provides only a rudimentary way to conduct drug repositioning using text mining tools on ClinicalTrials.gov. However, it could serve to stimulate other investigational initiatives to use clinical data to repurpose drugs, supplements, or even food to help prevent or treat diseases.

Serious adverse event data from randomized trials in the ClinicalTrials.gov were used because randomized trials are controlled experiments. However, ClinicalTrials.gov is only a tiny part of clinical data that could lead to the discovery of new use of existing drugs. Electronic medical record databases have much more clinical data than ClinicalTrials.gov. Other large sources of clinical data include the Federal Adverse Event Reporting System and social media (Nugent et al. 2016). These data could provide new information not only on marketed drugs, but also on supplements and food.

Computational drug repositioning usually involves the vast genome data and sophisticated machine learning techniques ( $\mathrm{Li}$ et al. 2016). In contrast, the work described here uses relatively small clinical trial data on ClinicalTrials.gov, which has been proved useful in other works to identify combination therapy (Wu et al. 2015) and pharmacogenomics information ( $\mathrm{Li} \& \mathrm{Lu}$ 2012). The algorithm presented here is simple and direct. Combining this work with text mining (Tari \& Patel 2014) may lead to better methodologies for drug repurposing.

Compared to traditional drug development, repositioned drugs have the advantage of decreased development time and costs given that significant toxicology and safety data will have already 
217 been accumulated, drastically reducing the risk of attrition during the drug discovery and

218 development process.

219

220

\section{Conclusions}

221 The rapidly growing clinical data could be extracted and analyzed for drug repositioning

222 utilizing text mining tools. Repositioning non-cancer drugs with low toxicity or even vitamin

223 supplements for cancer might provide tangible benefits for patients.

224

225

The method described could be used for drug repositioning not only for cancer but also for other diseases and symptoms reported as adverse events. It might help other investigators to develop better ways to utilize the fast growing data in ClinicalTrials.com to reposition drugs for unmet medical needs.

The work we described here could merely help identify possible new uses of existing drugs to be investigated further. Prospective clinical trials would be required to provide the necessary evidence to have such new uses approved by regulatory agencies.

235 The authors are grateful for the statistical review by Dr. Margaret Gamalo, the expert editing by Drs. Marjo Gazak and Jane Reed, and insightful advice and review by Dr. Stephen Ruberg. 
237

238

239

240

241

242

243

244

245

246

247

248

249

250

251

252

253

254

255

256

257

258

259

260

261

262

263

264

265

266

267

268

269

270

271

272

273

274

275

276

277

278

279

280

281

\section{References}

Ashburn TT, and Thor KB. 2004. Drug repositioning: identifying and developing new uses for existing drugs. Nat Rev Drug Discov 3:673-683.

Bandy J, Milward D, and McQuay S. 2009. Mining protein-protein interactions from published literature using Linguamatics I2E. Methods Mol Biol 563:3-13. 10.1007/978-1-60761$175-21$

Coelho ED, Arrais JP, and Oliveira JL. 2016. Computational Discovery of Putative Leads for Drug Repositioning through Drug-Target Interaction Prediction. PLoS Comput Biol 12:e1005219. 10.1371/journal.pcbi.1005219

Cormack J, Nath C, Milward D, Raja K, and Jonnalagadda SR. 2015. Agile text mining for the $2014 \mathrm{i} 2 \mathrm{~b} 2 / \mathrm{UTHealth}$ Cardiac risk factors challenge. J Biomed Inform 58 Suppl:S120-127. 10.1016/j.jbi.2015.06.030

Firnhaber C, Zungu K, Levin S, Michelow P, Montaner LJ, McPhail P, Williamson AL, Allan BR, Van der Horst C, Rinas A, and Sanne I. 2009. Diverse and high prevalence of human papillomavirus associated with a significant high rate of cervical dysplasia in human immunodeficiency virus-infected women in Johannesburg, South Africa. Acta Cytol 53:10-17.

Galijatovic-Idrizbegovic A, Miller JE, Cornell WD, Butler JA, Wollenberg GK, Sistare FD, and DeGeorge JJ. 2016. Role of chronic toxicology studies in revealing new toxicities. Regul Toxicol Pharmacol 82:94-98. 10.1016/j.yrtph.2016.10.010

Hodos RA, Kidd BA, Shameer K, Readhead BP, and Dudley JT. 2016. In silico methods for drug repurposing and pharmacology. Wiley Interdiscip Rev Syst Biol Med 8:186-210. $10.1002 / \mathrm{wsbm} .1337$

Hu J, Zhang LC, Song X, Lu JR, and Jin Z. 2015. KRT6 interacting with notch1 contributes to progression of renal cell carcinoma, and aliskiren inhibits renal carcinoma cell lines proliferation in vitro. Int J Clin Exp Pathol 8:9182-9188.

Juanola-Falgarona M, Salas-Salvado J, Martinez-Gonzalez MA, Corella D, Estruch R, Ros E, Fito M, Aros F, Gomez-Gracia E, Fiol M, Lapetra J, Basora J, Lamuela-Raventos RM, Serra-Majem L, Pinto X, Munoz MA, Ruiz-Gutierrez V, Fernandez-Ballart J, and Bullo M. 2014. Dietary intake of vitamin K is inversely associated with mortality risk. J Nutr 144:743-750. 10.3945/jn.113.187740

Kesic V, Petkovic S, and Milacic D. 1990. [Smoking and nonmalignant changes in the uterine cervix]. Srp Arh Celok Lek 118:201-204.

Li J, Chen L, Yu P, Liu B, Zhu J, and Yang Y. 2014. Telmisartan exerts anti-tumor effects by activating peroxisome proliferator-activated receptor-gamma in human lung adenocarcinoma A549 cells. Molecules 19:2862-2876. 10.3390/molecules19032862

Li J, and Lu Z. 2012. Systematic identification of pharmacogenomics information from clinical trials. J Biomed Inform 45:870-878. 10.1016/j.jbi.2012.04.005

Li J, Zheng S, Chen B, Butte AJ, Swamidass SJ, and Lu Z. 2016. A survey of current trends in computational drug repositioning. Brief Bioinform 17:2-12. 10.1093/bib/bbv020

Mullen J, Cockell SJ, Tipney H, Woollard PM, and Wipat A. 2016. Mining integrated semantic networks for drug repositioning opportunities. PeerJ 4:e1558. 10.7717/peerj.1558

Nugent T, Plachouras V, and Leidner JL. 2016. Computational drug repositioning based on sideeffects mined from social media. PeerJ Computer Science 2:e46. 10.7717/peerj-cs.46 
282

283

284

285

286

287

288

289

290

291

292

293

294

295

296

297

298

299

300

301

302

303

304

305

306

307

308
Pu Z, Zhu M, and Kong F. 2016. Telmisartan prevents proliferation and promotes apoptosis of human ovarian cancer cells through upregulating PPARgamma and downregulating MMP9 expression. Mol Med Rep 13:555-559. 10.3892/mmr.2015.4512

Qosa H, Mohamed LA, Al Rihani SB, Batarseh YS, Duong QV, Keller JN, and Kaddoumi A. 2016. High-Throughput Screening for Identification of Blood-Brain Barrier Integrity Enhancers: A Drug Repurposing Opportunity to Rectify Vascular Amyloid Toxicity. $J$ Alzheimers Dis. 10.3233/jad-151179

Sheskin J. 1965. Thalidomide in the Treatment of Lepra Reactions. Clin Pharmacol Ther 6:303306.

Tari LB, and Patel JH. 2014. Systematic drug repurposing through text mining. Methods Mol Biol 1159:253-267. 10.1007/978-1-4939-0709-0_14

Wei G, Wang M, and Carr BI. 2010. Sorafenib combined vitamin K induces apoptosis in human pancreatic cancer cell lines through RAF/MEK/ERK and c-Jun NH2-terminal kinase pathways. J Cell Physiol 224:112-119. 10.1002/jcp.22099

Wu CH, Bai LY, Tsai MH, Chu PC, Chiu CF, Chen MY, Chiu SJ, Chiang JH, and Weng JR. 2016a. Pharmacological exploitation of the phenothiazine antipsychotics to develop novel antitumor agents-A drug repurposing strategy. Sci Rep 6:27540. 10.1038/srep27540

Wu M, Sirota M, Butte AJ, and Chen B. 2015. Characteristics of drug combination therapy in oncology by analyzing clinical trial data on ClinicalTrials.gov. Pac Symp Biocomput:6879.

Wu TT, Niu HS, Chen LJ, Cheng JT, and Tong YC. 2016b. Increase of human prostate cancer cell (DU145) apoptosis by telmisartan through PPAR-delta pathway. Eur J Pharmacol 775:35-42. 10.1016/j.ejphar.2016.02.017

Zheng C, Guo Z, Huang C, Wu Z, Li Y, Chen X, Fu Y, Ru J, Ali Shar P, Wang Y, and Wang Y. 2015. Large-scale Direct Targeting for Drug Repositioning and Discovery. Sci Rep 5:11970. 10.1038/srep11970 